Published as: Vanoutrive, T., E. Van de Vijver, L. Van Malderen, B. Jourquin, I. Thomas, A. Verhetsel \& F. Witlox (2012) "What determines carpooling to workplaces in Belgium: location, organisation, or promotion". Journal of Transport Geography. Vol. 22 (1), pp. 77-86.

\title{
WHAT DETERMINES CARPOOLING TO WORKPLACES IN BELGIUM: LOCATION, ORGANISATION, OR PROMOTION?
}

\section{Introduction}

Carpooling is one of the many travel alternatives promoted by transport policies to reduce the amount of vehicles on the road. It was promoted during World War II to deal with oil and rubber shortages and during the oil crisis of the 1970s (Ferguson, 1997b; 2000; Gilbert and Perl, 2008). More recently, carpooling was also advocated during the 2008 Olympics in Beijing as a response to driving restrictions (Wang, 2011). Nowadays, carpooling is promoted by mobility management policies to put more emphasis on the issue of sustainable transport. The main targets here are a reduction of transport-related pollution $\left(\mathrm{PM}_{10}, \mathrm{NO}_{x}\right.$ and $\left.\mathrm{CO}_{2}\right)$, noise nuisance reduction and a decrease of congestion levels. These sustainable mobility policies are called mobility management or travel/transportation demand management (TDM) to stress that the focus is not on infrastructure supply but on managing the demand-side, i.e. using the transport system in the most optimal way to fulfil our lifestyle needs (Frändberg and Vilhelmson, 2010; Lyons and Urry, 2005).

Usually, commuting traffic is a major topic in mobility management schemes since most people commute to already congested urban areas during the peak travel period. The involvement of employers in transport policy is a logical consequence of this focus on commuting. Employers have a privileged relationship with their employees and are therefore regularly used as intermediaries between government and individual travellers (DeHart-Davis and Guensler, 2005; Ferguson, 1997b; 2007). Furthermore, employers are also more efficiently organized to implement mobility management measures such as parking restrictions, allowances and bicycle facilities. Finally, involving the private sector also reduces the burden of transport policies on the public budget (Cairns et al., 2008; Roby, 2010; Rye, 2002). 
Despite the policy focus on employers, commuting research traditionally focuses on individual commuters or on aggregated spatial units (e.g. municipalities). Standard mode choice research takes the individual or the household as the unit of observation since individual and household characteristics determine the choice process (Van Acker et al., 2010). The advantage of aggregating individuals in geographical areas on the other hand, is that the effects at higher geographical scales are understood. Indeed, one commuter does not cause a traffic jam; it is the concentration of commuters in particular places and at particular times of the day that can be considered as the main causes of congestion and pollution. We acknowledge the merits of both the individual and the area-wide perspectives. However, we argue that a workplace perspective might enrich transport research for a number of reasons. First, employers are used as intermediaries in mobility management strategies and the set of available carpool incentives differs between workplaces. Second, workplaces are physical locations with specific characteristics, even within a particular geographical area considerable differences in accessibility levels may exist between workplaces. Third, the workplace is more than a physical environment; it is also a social environment. Accordingly, what people at your workplace think and do (the subjective norm, corporate culture) influences your travel behaviour (Bonham and Koth, 2010; Heinen et al., 2011; McDonald, 2007; Van Acker et al., 2011).

The aim of the current study is to explain the differences in shares of carpooling among employees at large workplaces in Belgium. In contrast to studies like Habib et al. (2011) and Canning et al. (2010), which analysed respectively one and six employer-led carpooling schemes with more detail, we employ a large dataset containing several thousands of workplaces. Although our main focus is on workplaces, a multilevel perspective is used (Wegener, 2011). We conceptualise workplaces as meaningful units since they are physical and social environments, but we take into account that on a lower level, the behaviour and characteristics of individual actors matter (Whitmeyer, 1994). Therefore, we make use of Census data to provide the socio-demographics of carpooling in Belgium and we refer to individual characteristics while discussing differences between workplaces. By aggregating workplaces using on the one hand, activity sectors, and on the other hand, municipalities, we add levels of analysis above the workplace level. This multilevel approach implies that we can put the importance of workplaces into perspective.

The paper is organised as follows. In the next section, an overview of the characteristics and determinants of carpooling is given. Section 3 introduces the data employed in this paper. Next, 
an exploratory analysis is carried out (Section 4). Two perspectives were used; the first is a spatial one, as we assume that the modal split at workplaces is influenced by the context (location). Besides this exploratory spatial data analysis (ESDA), we explore the differences between activity sectors. In Section 5 the methodological framework is presented in which we use a multilevel regression model to explain the differences in the popularity of carpooling between workplaces. Section 6 reports the results of this model. Finally, we end with a discussion (Section 7) and a conclusion (Section 8).

\section{Definition and determinants of carpooling}

\subsection{Definition}

One single definition of carpooling does not exist. Furthermore, the terms carpooling, ridesharing and car-sharing may or may not be used interchangeably. In the broadest sense of the word, 'ridesharing exists when two or more trips are executed simultaneously, in a single vehicle.' (Morency, 2007, p. 240). We prefer to use the term carpooling since it stresses the formation of a pool, i.e. a relatively stable arrangement. We will not use the term car-sharing since this is regularly understood as a service in which a car can be booked by persons who only occasionally need a 'rental' car for e.g. their weekly trip to the supermarket.

In the literature most authors distinguish between household-based and non-household-based carpools which are also called internal and external carpools respectively (Buliung et al., 2010; Correia and Viegas, 2011; Ferguson, 1997a; Morency, 2007; Teal, 1987). This distinction is relevant for two reasons. First, members of the same household have their trip origin in common; as a result, no time is lost for picking up a passenger. Second, the level of trust is high between members of the same household and this is considered to be important in the formation of carpool clubs. Therefore, Correia and Viegas (2011) classify relations between carpool members on the basis of the level of trust which is assumed to be higher between members of the same household than between (in decreasing order of trust) friends, colleagues and unrelated persons.

Some authors classify carpool trips on the basis of the types of matching between origins and destinations (Morency, 2007; Rietveld et al., 1999). The most simple carpool structure encompasses that both driver and rider(s) have their origin and destination in common. If origins and/or destinations are not the same, more complex structures appear. Furthermore, carpool members can meet at a carpool parking at an intermediate location. All this makes of carpooling 
a complex and hybrid concept. Accordingly, it is no coincidence that the two data sources used in this paper employ a different definition of carpooling.

\subsection{Determinants of carpooling}

Most studies do not detect strong correlations between socio-demographics and carpooling propensity (Buliung et al., 2010; Canning et al., 2010; Ferguson, 1997a; Teal, 1987). Nevertheless, some general patterns appear. Lower income classes seem to be associated with a higher propensity to carpool, for the most part in the form of internal carpools. The income variable is associated with vehicle ownership and auto availability. Furthermore, members of multiple worker households carpool more since match-making is easier within the household and car availability is limited. More educated employees carpool less, a factor which also relates to income. Unsurprisingly, females with young children carpool less since their commuting trips are often more complex as they have to drop of and/or pick up children at school or nursery.

Psychological barriers, attitudes and perceptions seem to have a larger influence on the decision to carpool than socio-demographics. Drivers dislike a delegation of control and positively experience their solitary personal space (Gardner and Abraham, 2007). Privacy issues and the fear to ride with strangers thus limit the potential of carpooling, although a minority positively values the 'more sociable travel'. However, financial motives and environmental concern are considered more important attitudinal factors than the social aspect (Canning et al., 2010).

The literature states that carpool commuting trips are generally longer than the journeys of single occupant vehicle (SOV) drivers (Ferguson, 1997a). However, the relation between distance and carpooling is multifaceted. First, a driver often needs to make a detour to pick-up or drop-off the passenger. This extra travel is also known as circuity (Shoup, 1997, p. 205), and Rietveld et al. (1999) estimate a travel time increase of $17 \%$ compared with solo driving (based on a limited sample). This pick-up/drop-off delay and extra travel and waiting time make carpooling less suitable for short distances. Second, the savings made by sharing travel costs increase with distance which makes carpooling more attractive for longer trips. Third, 'pool geography' is related to distance. Finding a carpool partner with the same origin and destination zone may be difficult, especially in low-density areas (Tsao and Lin, 1999) and at larger distances from the destination. As a result, Buliung et al. (2010) note that there is a threshold distance above which carpooling is less likely to occur, besides the positive relationship 
between distance and carpool propensity. They also stress the importance of the pool-size effect, which is present both at the origin and destination side of the trip. The spatial clustering of commuters at the home-end is a crucial factor in the formation of carpools, but also firm size matters since a larger pool of employees within the same work environment increases the number of potential carpool partners. Similar work schedules and higher levels of trust between colleagues (Correia and Viegas, 2011) further increase the potential of workplaces as matching places.

Considering spatial structure, the more congested downtown areas, associated with a high transit access, less parking availability and higher parking costs, are stronger correlated with a higher use of SOV alternatives (Hwang and Giuliano, 1990). However, when public transport is of good quality, carpooling is less attractive since congestion and parking scarcity remain obstacles for car commuting to city centres. Therefore, Teal (1987, p.211) concludes that 'carpooling picks up the slack for transit in environments where the latter is of poor quality'.

\subsection{The promotion of carpooling}

A particular set of carpooling determinants are the (dis)incentives present in mobility management schemes which aim to increase the popularity of carpooling. The rationale behind the promotion of carpooling is that every carpooling employee implies one car less on the road. The quoted benefits of carpooling are self-evident: driving costs may be shared (drivers may get compensation, because passengers pay a part of the commuting cost and still enjoy the comfort of a car), and commuters are not dependent on schedules and/or public transport networks. However, the majority of workers does not carpool, the advantages of carpooling are most of the times not strong enough to entice commuters to give up the comfort of driving alone (Comsis Corporation, 1993; Hwang and Giuliano, 1990; Kingham et al., 2001; Tsao and Lin, 1999). Therefore, a variety of instruments are used to promote carpooling.

Given the low cost of most measures that encourage carpooling, employers indicate them as acceptable, with the exception of parking restrictions (Rye, 1999a; 1999b). Most research classifies the guaranteed ride home as effective (Correia and Viegas, 2011; Giuliano et al., 1993; Kingham et al., 2001; Menczer, 2007; Rye, 1999a, 1999b). However, Hwang and Giuliano (1990) identified it as less effective, together with other 'carrots' like preferential parking, alternative work hours, a matching service, and marketing. In what follows, we put the effectiveness of measures into perspective. As Canning et al. (2010) point out, the success of 
preferential parking depends on the actual parking pressure at a site. Regarding work schedules, most studies state that a regular work schedule facilitates finding carpool-partners with the same working hours and that flexible work schedules positively influence public transport patronage. Flexitime and the promotion of carpool are then seen as conflicting mobility management measures (Buliung et al., 2010; Huang et al., 2000). However, although a flexible work arrangement reduces the probability that carpooling enters the choice set of a commuter, once the commuter perceives carpooling as a viable option, there is a positive effect of flexitime on carpooling (Habib et al., 2011). Obviously, the development of ICT brings along more advanced (on-line) carpool-matching tools (Buliung et al., 2010; Canning et al., 2010). Some of these tools try to overcome the poor schedule flexibility and offer a dynamic ride-matching service. This involves the creation of a large pool of potential carpoolers which are matched in a flexible way without the necessity to carpool every day and each time with the same person(s) (Correia and Viegas, 2011). It is yet unclear whether these casual carpooling strategies can substantially increase the number of carpool trips. A last 'soft' measure to promote carpooling is marketing. This, and information provision in general, is needed to inform the audience about the carpool measures that exist. Although information provision is considered as cheap, a tailormade approach might require significant budgets, especially if an in-house carpool coordinator is present (Buliung et al., 2010).

Hwang and Giuliano (1990) indicate that 'sticks' like parking charges and restrictions, and transport allowances as more effective than 'carrots' like marketing, preferential parking and setting up a matching service. Also Kingham et al. (2001) point to financial incentives as measures with a high potential. The potential attributed to parking charges and restrictions is in line with the general finding that 'sticks proved to have a generally greater influence on stated mode choice than the carrots' (O'Fallon et al., 2004, p. 28). However, as is clear from the discussion above, there is no consensus about the effectiveness of measures promoting carpooling.

\section{Data}

The aim of the present paper is to analyse carpooling in Belgium using a workplace perspective. Therefore, we need data that is national in scope and that provides data on workplace-related factors like work schedules and mobility management measures. As main source of data we employ the Belgian database home-to-work-travel (HTWT) 2005. This database is the result of a mandatory questionnaire about the home to work displacements and the mobility 
management measures at large workplaces in Belgium (Vanoutrive et al., 2010). A large workplace is defined as a site containing at least 30 employees of a company with at least 100 employees. The database HTWT 2005 contains 7460 work sites with at least 30 employees which employ 1342119 employees in total. In addition, we will also use data stemming from the Belgian 2001 Census for illustrative and comparative purposes (Verhetsel et al., 2009). This census does not contain information on mobility management initiatives at workplaces and other organisational characteristics. Nevertheless, it helps to complete the picture of carpooling in Belgium.

Please note that the definition of carpooling differs between the two data sources. The questionnaire HTWT only collects information on external carpools (without family members) while the 2001 Census includes household-based (internal) carpools. For an employer it can be hard to distinguish between household- and non-household-based carpools. For this and other reasons the quality of figures reported by employers is likely to be variable. However, the obligatory discussion of the questionnaire with the representatives of the employees (unions) in the works council, acts as a kind of quality check, together with some extra quality checks carried out by the Federal Public Service Mobility and Transport.

\section{Exploratory data analysis}

The 2001 (i.e. most recent) Belgian Census produces some basic facts about carpooling in Belgium (Table 1). In Belgium, 6.1\% (203 024 commuters) of the workforce commutes as a car passenger, $66.1 \%$ as a car driver, $6.5 \%$ uses the bicycle, $6.0 \%$ is a rail user, $6.2 \%$ uses regional public transport (bus, tram or metro) while other modes have a share below $5.0 \%$. If we assume that each passenger shares a car with one driver (cf. Buliung et al., 2010), the share of carpool is $12.3 \%$. This figure is comparable to levels observed in the US and Canada (Buliung et al., 2010), but a major difference with the US is the higher share of public transport in Belgium (12.2\%). This can be explained by the more extensive public transport systems in Belgium and other parts of Europe (Buehler, 2011; Vanoutrive et al., 2012). The Belgian Census revealed that women carpool more than men. In contrast with the general belief that carpooling suits better with longer commutes, (solo) car drivers and rail commuters travel more kilometres to their workplace. The high average commuting distance in Belgium may be an explanation for this fact. A clear spatial pattern appears when mapping the share of carpooling residents per municipality (Figure 1, Verhetsel et al., 2009). Commuters who live in the northwest of Belgium or in the Brussels Capital Region carpool less than average. These are the areas with lower 
average commuting distances (Boussauw and Witlox, 2009). Carpooling is more popular in the south of the country, especially on the former industrial east-west axis (which contains cities like Charleroi $(C)$ and Liège $(L)$ ), and in the east. Note that south of this axis, Belgium is less densely populated. However, our focus is not on the place of residence, but on the work end of the commuting trip. Therefore, we now turn to an analysis of the workplace data in the database HTWT. Figure 1 shows a clear spatial pattern of carpooling, measured at the place of residence. Therefore, we start the examination of the database HTWT with an exploratory spatial data analysis (ESDA), to investigate whether a spatial structure at the work end of the commute is present or not.

\section{Insert Table 1 here}

Table 1: Basic figures on carpooling in the 2001 Census

\begin{tabular}{ll}
\hline percentage of commuters that carpool (passenger) & 6.1 \\
percentage of female carpooling commuters & 59 \\
average commuting distance (single trip, in km) & \\
car as passenger & 17.6 \\
car driver & 20.1 \\
rail & 46.6 \\
overall & 19.1 \\
average commuting time (towards workplace, in minutes) & 26 \\
car as passenger & 27 \\
car driver & 66 \\
rail & 29 \\
$\quad$ overall &
\end{tabular}

Insert Figure 1 here

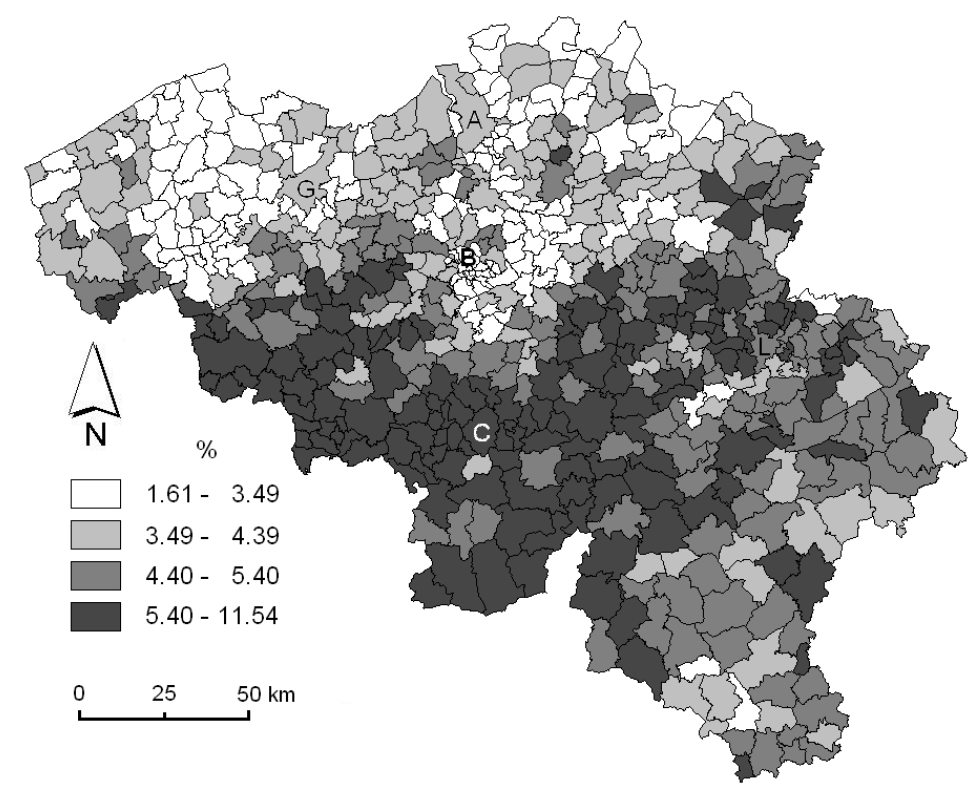


Figure 1: Share of carpooling in commuting per municipality of residence (Data source: Belgian 2001 Census; cartography by the authors; equal group sizes)

Major cities: A: Antwerp; B: Brussels; C: Charleroi; G: Ghent; L: Liège

\subsection{Exploratory spatial data analysis (ESDA)}

The accessibility of a workplace is a function of its location. Since accessibility (and thus location) is a mode choice determinant, we might expect a spatial pattern when mapping the shares of carpooling in Belgium. Therefore, we start the analysis with an exploratory spatial data analysis (ESDA). The variable of interest is the percentage of employees at a worksite which carpools to make the daily commute. According to the database HTWT 2005, on average $3.31 \%$ of the employees on a worksite are carpooling. To analyse the spatial pattern of carpooling among Belgian workplaces, the workplaces in the database HTWT are aggregated at the municipality level. One of the main issues in ESDA is the measurement of spatial autocorrelation. Observations are spatially autocorrelated if the values of neighbouring municipalities are more similar than those of more distant observations. The most common statistic to measure the overall spatial autocorrelation is the Moran's I, which ranges between -1 (negative spatial autocorrelation) and +1 (positive spatial autocorrelation) (Getis, 2007; Legendre, 1993). Using the data of the 2001 Census (Figure 1), the Moran's I statistic confirms the presence of a clear spatial pattern at the place of residence ( 0.55 taking into account all municipalities within a range of $20 \mathrm{~km}$, and 0.70 when using the four nearest municipalities). However, using the database HTWT, a low value for the Moran's I statistic indicates the absence of spatial autocorrelation (0.056, taking all municipalities within a range of $20 \mathrm{~km}$ as neighbours). Note that there are significant differences between the two datasets (definition of carpooling, place of residence versus workplace, all commuters versus only large companies). The map with the average share of carpooling per municipality (Figure 2) confirms the absence of a clear spatial pattern. Besides statistics which measure the overall spatial autocorrelation, local indicators of spatial association (LISA) exist (Anselin, 1995). A LISA indicates for each observation how different its value is from neighbouring observations. Based on this LISA, spatial clusters can be defined as shown in Figure 3. On the LISA map (Figure 3), a cluster of municipalities with low carpool shares is situated in the centre of the country and carpooling seems more popular in the east and in some other more peripheral locations. Note that these maps are based on data about the destination of the home to work trip. There is a notable contrast with the map of the share of carpooling per municipality of residence in Figure 1. 


\section{Insert Figure 2 here}

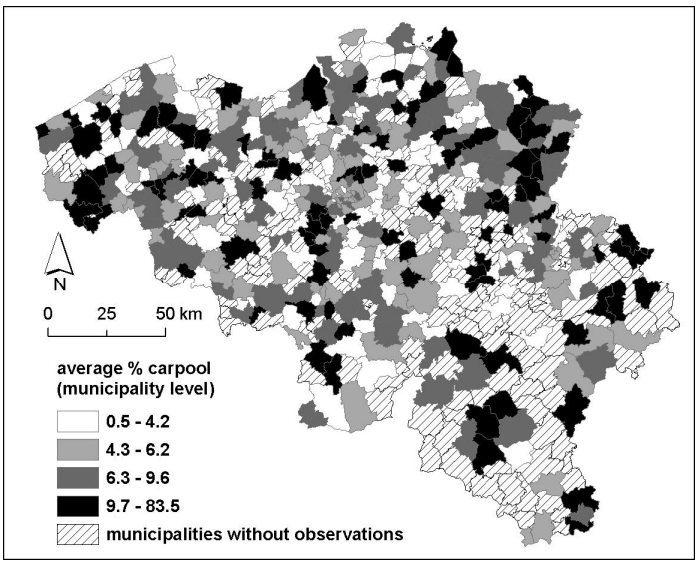

Figure 2: Map of carpool share per municipality (work location)

Source: database HTWT 2005 (cartography by the authors; natural breaks)

\section{Insert Figure 3 here}

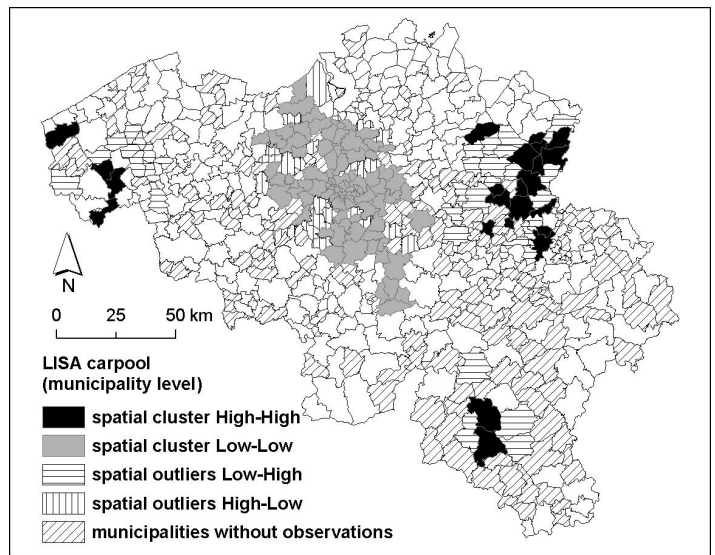

Figure 3: LISA map of carpool share per municipality (work location) Source: database HTWT 2005; Software: Geoda (Anselin, 2005) and ArcGIS (ESRI) LISA statistic takes all municipalities into account within a range of $30 \mathrm{~km}$ (cartography by the authors) 


\subsection{The promotion of carpooling}

Table 2 shows the carpool-related mobility management measures which could be indicated in the questionnaire HTWT. Figures are given for the whole sample $(n=7460)$ as well as for a subsample which only contains workplaces where at least one employee carpools $(n=3353)$. In both samples, the majority of the workplaces do not report carpool-related mobility management measures. The organisation of carpooling, connecting to a central carpool database and the delivery of information about carpooling, are relatively the most common measures, while preferential parking for carpooling employees and the organisation of a guaranteed ride home are rare.

\section{Insert Table 2 here}

Table 2: Percentage of worksites where carpool-promoting measures are taken

\begin{tabular}{lll} 
Carpool promoting measure & $\begin{array}{l}\text { all sites } \\
(\mathrm{n}=7460)\end{array}$ & $\begin{array}{l}\text { sites with CP- } \\
\text { employees } \\
(\mathrm{n}=3353)\end{array}$ \\
\hline 'Organising a car pool on the site' & 5.2 & 6.5 \\
'Connecting to a central database' & 4.6 & 5.7 \\
'Dispersion of information about carpooling' & 4.2 & 5.0 \\
'Reserved parking places for carpooling employees' & 1.9 & 2.4 \\
'Guaranteed ride home for carpool passengers & 1.6 & 1.9 \\
$\quad$ in case of unpredicted circumstances' & & 83.9 \\
\hline
\end{tabular}

Source: questionnaire HTWT 2005

\subsection{Activity sector}

In the previous paragraphs we focused on the location-related differences between workplaces and on the measures taken to promote carpooling. However, workplaces also differ for organisational reasons. Therefore, the workplaces were classified in 19 activity sectors by means of the Crossroads Bank for Enterprises (CBE) code of every company in the database HTWT. With this code we identified the economic sector (Nacebel 2003, based on the European NACE Statistical Classification of Economic Activities in the European Community) using the BELFirst database. Almost half of the sites (3445) could not be linked to an economic sector on the basis of their CBE code. We explored the data and it turned out that these sites are mostly found in health, education, public transport and other government sectors. We classified these workplaces semi-automatically on the basis of keywords in the names of the institutions. This could be done since names of institutions in the public sector often contain official abbreviations. We inspected the database and could not detect misclassified workplaces. In general, $13 \%$ of the variance in carpooling at Belgian worksites can be attributed to the activity sector. We will 
explain the estimation of this variance partitioning in Section 6. Table 3 shows the different economic sectors together with their average number of carpool-oriented mobility management measures (see Table 2) and the share of carpool in the modal split. The construction sector is definitely the 'number one' in carpooling. Other carpool-oriented sectors are manufacturing, electricity, gas and water, and transport warehousing and communication. Low levels of carpooling are found for universities, post, public transport companies and in the health sector. The financial sector and universities take most measures to promote carpooling. Police, post and public transport companies take the least measures to promote carpooling.

\section{Insert Table 3 here}

Table 3: Average percentage of carpooling employees at a worksite, average number of carpoolmeasures and number of worksites per economic sector

\begin{tabular}{|c|c|c|c|c|c|c|c|c|}
\hline \multirow[t]{2}{*}{ economic sector } & \multicolumn{2}{|c|}{$\begin{array}{l}\text { average } \% \\
\text { carpoolers }\end{array}$} & \multicolumn{2}{|c|}{$\begin{array}{l}\text { average CP- } \\
\text { measures }\end{array}$} & \multicolumn{2}{|c|}{ \# worksites } & \multicolumn{2}{|c|}{ \# employees } \\
\hline & $\begin{array}{l}n= \\
7460\end{array}$ & $\begin{array}{l}n= \\
3353\end{array}$ & $\begin{array}{l}n= \\
7460\end{array}$ & $\begin{array}{l}n= \\
3353\end{array}$ & $\begin{array}{l}n= \\
7460\end{array}$ & $\begin{array}{l}\mathrm{n}= \\
3353\end{array}$ & $\begin{array}{l}n= \\
7460\end{array}$ & $\begin{array}{l}n= \\
3353\end{array}$ \\
\hline Construction & 10.34 & 24.28 & 0.23 & 0.28 & 108 & 46 & 13927 & 7681 \\
\hline Manufacturing & 6.82 & 9.81 & 0.23 & 0.23 & 1092 & 759 & 315246 & 248855 \\
\hline $\begin{array}{l}\text { Transport, warehousing } \\
\text { and communication }\end{array}$ & 6.53 & 11.56 & 0.25 & 0.23 & 280 & 158 & 58232 & 36117 \\
\hline Electricity, gas and water & 5.92 & 9.67 & 0.16 & 0.17 & 116 & 71 & 16786 & 12433 \\
\hline $\begin{array}{l}\text { Other community, social } \\
\text { and personal services }\end{array}$ & 4.71 & 9.09 & 0.31 & 0.27 & 199 & 103 & 30048 & 19734 \\
\hline Primary sector & 3.75 & 6.01 & 0.29 & 0.47 & 24 & 15 & 3393 & 2262 \\
\hline $\begin{array}{l}\text { Public administration, defence, } \\
\text { social security insurance }\end{array}$ & 3.18 & 7.09 & 0.12 & 0.13 & 752 & 337 & 142001 & 87361 \\
\hline $\begin{array}{l}\text { Real estate, renting } \\
\text { and producer services }\end{array}$ & 3.00 & 7.17 & 0.24 & 0.26 & 344 & 144 & 56457 & 31264 \\
\hline Local government & 2.88 & 5.56 & 0.07 & 0.08 & 664 & 344 & 93511 & 56937 \\
\hline Non profit & 2.77 & 5.53 & 0.28 & 0.36 & 192 & 96 & 31079 & 19994 \\
\hline Finance & 2.60 & 4.28 & 0.92 & 0.96 & 184 & 112 & 58933 & 48165 \\
\hline Education & 2.16 & 6.89 & 0.08 & 0.11 & 917 & 288 & 87610 & 32277 \\
\hline Hotels and restaurants & 2.12 & 7.93 & 0.12 & 0.26 & 86 & 23 & 9124 & 4163 \\
\hline $\begin{array}{l}\text { Wholesale and retail; } \\
\text { repair of motor vehicles } \\
\text { and consumer goods }\end{array}$ & 1.93 & 6.58 & 0.14 & 0.19 & 877 & 257 & 97912 & 43888 \\
\hline Police & 1.76 & 3.80 & 0.02 & 0.05 & 95 & 44 & 13777 & 8433 \\
\hline Health & 1.58 & 3.57 & 0.13 & 0.15 & 653 & 290 & 185552 & 131993 \\
\hline Public Transport Companies & 1.57 & 4.17 & 0.02 & 0.02 & 231 & 87 & 42250 & 27400 \\
\hline Post & 1.51 & 5.79 & 0.03 & 0.04 & 306 & 80 & 29399 & 15000 \\
\hline $\begin{array}{l}\text { Universities and other } \\
\text { higher education institutions }\end{array}$ & 1.05 & 3.59 & 0.40 & 0.62 & 340 & 99 & 56882 & 26874 \\
\hline Total & 3.31 & 7.36 & 0.18 & 0.22 & 7460 & 3353 & 1342119 & 860831 \\
\hline
\end{tabular}

Source: questionnaire HTWT 2005

Notes. CP-measures: these are the measures shown in Table 2;

$n=7460$ : full sample; $n=3353$ : only workplaces where at least one employee carpools 


\section{Multilevel regression analysis}

To complement the exploratory analysis, we apply multilevel regression analysis to better understand the differences in carpooling among workplaces in Belgium. Since the activity sector to which a workplace belongs appeared to be relevant, we apply multilevel modelling. This type of regression models explicitly takes into account that observations are nested in groups, while standard regression analysis assumes the independence of observations. More concretely, this independence assumption is violated if workplaces in the same economic sector or workplaces in the same area are not independent. The main aim of multilevel regression models is to deal with this grouping of observations (Goldstein, 1995; Hox, 2002; Luke, 2004). In fact, the regression model estimates a separate regression line for every group (i.e. economic sector). If these regression lines run in parallel, the model is called a random intercept model (each line has a different intercept). If the regression lines have different slopes (and different intercepts), it is referred to as a random slope model. As in standard regression analysis, the linear multilevel regression model can be transformed in a logistic regression to analyse a binary dependent variable using a logit function.

Multilevel modelling has the advantage of getting a better understanding and more clear interpretation of the effects of higher levels (by estimating and reporting random effects). Furthermore, standard regression analysis ignores the grouping of data and this can cause underestimated standard errors of regression coefficients (Goldstein, 1995; Hox, 2002; Maas and Hox, 2004; Rasbash et al., 2005; Schwanen et al., 2004). The main disadvantage is that models become more complex. As a consequence, diagnostics can be more complicated as well. The comparison of different models is often used to evaluate a model. In what follows, we will refer to the so-called empty model (model A), i.e. a model with a multilevel structure (an extra error term) but without any independent variables. The empty model is then compared with the full model (model B), i.e. the multilevel model with the full set of independent variables.

Following independent variables were included in the multilevel analysis. As measure for the size of a site, the number of employees is used. The percentage of staff with a fixed (regular) work schedule is also considered. To account for site accessibility, three variables are used. First, the accessibility by car is measured as the potential number of people that can reach a given municipality and is calculated by Vandenbulcke et al. (2007, 2009). Rail accessibility is seen as the inverse of the sum of waiting and walking time between workplace and railway 
station, the calculation method and an example are given in Vanoutrive et al. (2012). Besides these activity-based accessibility indicators, congestion is introduced as an infrastructure-based accessibility indicator. The congestion variable is a dummy with a value of 1 if an employer indicated in the HTWT survey that the site suffers from road congestion, and 0 if not. Parking availability is defined as the number of parking places per employee; the maximum is set to 1 in order to avoid the effect of large customer parking spaces of shops and the like.

All non dummy variables are manipulated. To reduce the skewness of the variables, the logarithm is taken, except for the parking variable. Next, all independent variables are standardized using z-scores to make results comparable and to centre the variables. This centring is relevant since a random slope model is used (Luke, 2004). Finally, the standardized logarithm of the number of employees is centred around the value which corresponds to 200 employees. This number falls between the average (257) and the median (139) of the dataset used in the random slope model (model B). In more than half of the worksites (4107 of 7460) no employees carpool. These worksites are excluded from the main analysis (models $A$ and $B$ ) to avoid biases caused by zero inflated data. Nevertheless, a logistic regression (model C) is made to show the difference between sites without (0) and the sites with (1) carpooling employees.

\section{Results}

Table 4 lists the results of three multilevel models which used the Belgian database HTWT 2005. These models are estimated using MLwiN (Rasbash et al., 2009). First, the empty model (Model A), i.e. a model with a multilevel structure but without independent variables, indicates that $13 \%$ of the variance in carpooling at Belgian worksites can be attributed to the economic sector level, while the remaining $87 \%$ is variance between worksites, which also covers the variation between individual employees. In the concrete, $13 \%$ is the portion of the variance attributed to the economic sector $(0.027$ in model $A)$, relative to the total variance $(0.027+$ 0.188).

The second model (referred to as model B) is the random slope model. The results of the fixed part of the model can be interpreted in the same way as results of a standard regression model. In general, small worksites have high shares of carpooling, as have sites with more parking space per employee. More employees with a regular work schedule positively influence the success of carpooling. The lower the accessibility by car and by train, the more popular 
carpooling is, while the effect of congestion is less clear. Considering the mobility management measures, only the guaranteed ride home has a positive, significant relation with carpooling and the result for information delivery even has a negative sign, while the other variables are not significant at the $95 \%$ confidence interval. The random part of the model indicates that there are significant differences in carpool levels between activity sectors and that these differences are larger between small workplaces than between large workplaces. Figure 4 shows the intercepts for the different economic sectors (the level 2 residuals). The black dots show the differences between activity sectors after controlling for the variables included in model B while the grey dots are the reference (model $A$ ). On average, model $B$ explains $11 \%$ of the variance between workplaces (0.027-0.024/0.027, comparing model A with B).

Third, a logistic regression model (model C, Table 4) examines the difference between worksites where nobody carpools (0) and sites where at least one employee is carpooling (1). The results of this model are informative with respect to the omitted observations in the other two models. Model $\mathrm{C}$ shows that the probability of at least one carpooling employee is higher if more employees are working on the site, which is quite evident. This result supports the literature which states that more employees imply more possible carpool partners (pool-size effect). Nevertheless, at sites where at least one employee carpools, there is a negative sizeeffect (model B). One potential explanation is the fact that our dataset contains only larger sites ( $\geq 30$ employees), as a consequence, the majority of workplaces employ more than 100 employees. Presumably, the pool-size effect would be positive if also small workplaces were included. Furthermore, large concentrations of workers have generally better access to public transport and since the rail accessibility variable does not cover bus services and the like, the negative size-effect can be explained by stronger competition between carpooling and collective transport at larger sites. Finally, the level of trust between employees may be lower at large workplaces consisting of different separate subunits.

\section{Insert Table $\mathbf{4}$ here}

Table 4: Results of the multilevel regression analysis

\begin{tabular}{|c|c|c|c|c|c|}
\hline \multirow{6}{*}{$\begin{array}{l}\text { random part: } \\
\text { level } 2 \text { constant/constant } \\
\text { level } 2 \text { employees/const } \\
\text { level } 2 \text { employees/employees } \\
\text { level } 1 \text { constant/constant }\end{array}$} & $\begin{array}{l}\text { A } \\
\text { empty model }\end{array}$ & \multicolumn{2}{|c|}{$\begin{array}{l}\text { B } \\
\text { random slope model }\end{array}$} & \multicolumn{2}{|c|}{$\begin{array}{l}\mathrm{C} \\
\text { logit model }\end{array}$} \\
\hline & $\begin{array}{ll}\text { est. } & \text { s.e. }\end{array}$ & est. & s.e. & & \\
\hline & $0.027 \quad 0.009$ & 0.024 & 0.009 & 0.132 & 0.050 \\
\hline & & 0.006 & 0.003 & & \\
\hline & & 0.003 & 0.001 & & \\
\hline & $0.188 \quad 0.005$ & 0.173 & 0.004 & & \\
\hline
\end{tabular}


fixed part:

constant

employees

$0.604 \quad 0.039$

$0.560 \quad 0.038$

$0.259 \quad 0.095$

regular

$-0.087 \quad 0.016$

$\begin{array}{ll}0.733 & 0.029\end{array}$

parking

$\begin{array}{lll}0.041 & 0.008\end{array}$

$\begin{array}{ll}0.243 & 0.028\end{array}$

car accessibility

$\begin{array}{ll}0.010 & 0.008\end{array}$

$\begin{array}{ll}0.026 & 0.027\end{array}$

rail accessibility

$\begin{array}{ll}-0.048 & 0.008\end{array}$

$\begin{array}{ll}-0.048 & 0.028\end{array}$

congestion

mobility management:

organisation of carpool

$\begin{array}{ll}-0.022 & 0.008\end{array}$

$\begin{array}{ll}-0.022 & 0.028\end{array}$

$0.030 \quad 0.016$

$\begin{array}{ll}0.084 & 0.057\end{array}$

carpool database

preferential parking

$0.033 \quad 0.033$

$\begin{array}{ll}0.197 & 0.126\end{array}$

$\begin{array}{lll}0.010 & 0.037\end{array}$

$\begin{array}{ll}0.422 & 0.137\end{array}$

guaranteed ride home

$0.020 \quad 0.051$

$\begin{array}{ll}-0.196 & 0.192\end{array}$

information delivery

$\begin{array}{ll}0.122 & 0.054\end{array}$

$\begin{array}{ll}0.010 & 0.208\end{array}$

$\begin{array}{ll}-0.083 & 0.038\end{array}$

$-0.024 \quad 0.140$

-2 loglikelihood

3971.96

3706.79

level 2 (activity sector) $n=19$

level 1 (workplace) $n=$

19

3353

3353

19

7460

Notes. Dependent variable Model A and B: log(\%carpooling employees at a site); Dependent variable Model C: dummy variable: 0 if \#employees that carpool=0; 1 if \#employees that carpool>0; italics: not significant

Characteristics of raw data: number of employees: min.: 30, max.: 6552 (both samples); mean: 256.7 (model B), 179.9 (model C); percentage of staff with a regular (fixed) work schedule: min.: 0, max.: 100 (both samples); mean: 38.9 (model B), 36.6 (model C); number of parking places per employee: min.: 0, max.: 1 (both samples); mean: 0.51 (model B), 0.49 (model C); congestion (dummy variable): frequency: 27.4 (model B), 26.1 (model C); mobility management dummy variables: see Table 4; other variables are relative measures. All non-dummy variables are standardised (mean: 0 , standard deviation: 1 ).

\section{Insert Figure 4 here}

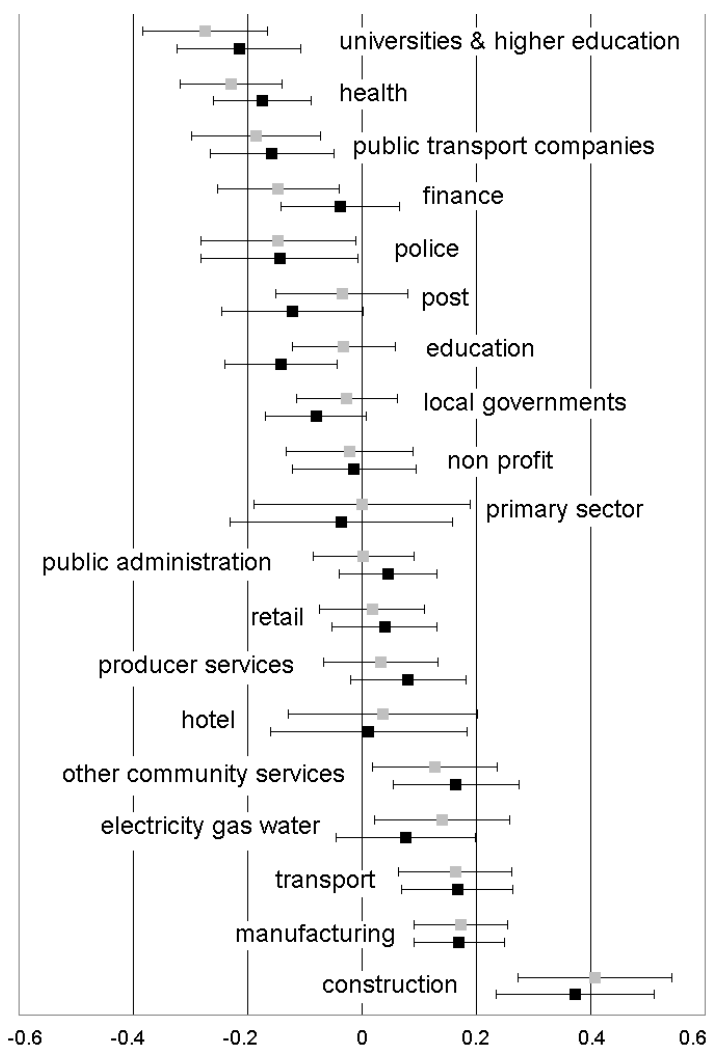


Figure 4: Level 2 (workplace) residuals of model A (grey) and model B (black) together with their 95\% confidence intervals

In the exploratory spatial data analysis (ESDA), both the computed Moran's I and Figure 3 revealed a (small) spatial effect in carpooling at the municipality level. To test whether this spatial effect is a source of unexplained variance, we estimated a two-level empty model of the workplace (level 1) residuals of model B with the municipality as second level. The variance at the municipality level was not significant (t-value: 1.85 ) and only $1 \%$ of the variance could be attributed to this level. Hence, the model accounts for the spatial pattern in the data and as a consequence, the unexplained variance cannot be attributed to differences between municipalities. The result for the car and rail accessibility variables indicate that carpooling is more abundant in the more peripheral areas of Belgium, as already indicated by the exploratory map in Figure 3. This confirms the literature which suggests that carpooling is particularly successful in places with a lack of public transport services.

\section{Discussion}

Given the potential competition between carpooling and public transport, the promotion of carpooling in public transport-rich areas can be a counterproductive mobility management strategy. Therefore, we follow the line of reasoning developed by Wang (2011) who states that governments should remove unnecessary barriers to carpooling, but that excessive subsidies to carpooling are detrimental to collective welfare since bicycles and public transport produce less emissions and use space more efficiently. Unwanted barriers to carpooling are taxation and insurance issues like the uncertainty of being insured while making a detour to pick up a passenger or when using a company car. 'Innocent' carpool incentives are on-line ride-matching services, preferential parking and guaranteed ride home services (preferably also applicable to public transport). In contrast, allowances or free parking for carpoolers in areas with high parking costs is oversubsidising since public transport is most of the times a viable alternative in these areas. For the same reason, we do not advise the introduction of carpool lanes in Belgian cities. Analogously, carpool parkings and park and ride facilities should be carefully planned since they often generate additional traffic and encourage car-oriented land use development outside urban areas (Meek et al., 2008; Parkhurst, 2000). If carpooling is heavily promoted at a workplace due to a lack of public transport, one should always check whether this is caused by bad land use planning or poorly organized public transport. Workplaces can be located outside 
agglomerations for safety and environmental reasons and carpooling might be the most efficient way to reduce levels of SOV driving in such cases. However, the clustering of businesses in e.g. chemical industrial parks (Reniers et al., 2010) creates the opportunity to invest in bus services as can be observed in the Antwerp port area where large chemical companies have established an extensive network of bus routes. When scale effects are absent, carpooling might be preferred over collective transport. Also for companies with particular characteristics, there are few alternatives to carpooling to reduce levels of SOV commuting. A noticeable example is the construction sector where the changing location of work makes of ridesharing the most rational way of travelling. Note that in this case it is hard to distinguish between carpooling/ridesharing and transport organized by the employer (Meersman et al., 1998). The high levels of carpooling in construction, manufacturing and transport (Table 3, Figure 4) indicate that in these sectors, carpooling has the highest potential to reduce the amount of SOV commuters. As discussed earlier, the promotion of carpooling may, however, not result in increased urban sprawl or lower levels of public transport or bicycle use.

Although transport professionals should be aware of the possible unintended consequences of carpool-oriented measures, their potential impact is still a relevant issue from a policy perspective. We included five dummy variables in our regression model which indicated the presence of carpool incentives at a workplace. A regression does not assume a causal relationship, nevertheless, the results might be indicative for the impact of the measures. In the main model, we omitted workplaces without carpooling employees which excludes the possibility that the absence of carpooling employees causes the absence of carpool measures. Furthermore, we controlled for location, accessibility and economic sector effects and only for the guaranteed ride home a positive significant result appeared. Note that this is a crosssectional analysis and that more advanced research designs can more comprehensively evaluate the effectiveness of measures. However, the relative low amount of explained variance makes methods like 2SLS less suitable. Also note that the guaranteed ride home is only present at $1.9 \%$ of the workplaces which makes the extrapolation of its effect less reliable. Some carpool measures might be successful at some sites, but in general, they do not seem to contribute much to the success of carpooling. Measures are often part of general HRM and corporate sustainability strategies and these general strategies often lack the right mix of measures to tackle the site-specific accessibility problems. Finally, some authors classify the investigated mobility management measures as less effective and expect more from financial incentives and 'hard' parking restrictions. However, we obtained a non significant estimate for 
the parking pressure variable. This lack of significance might be attributed to the correlation between the parking and the accessibility variables. The number of parking places per employee (parking index) is remarkably lower inside agglomerations (average 0.46) than outside (0.58; Belgian agglomeration as defined by Luyten and Van Hecke, 2007). Excluding the two aforementioned accessibility variables, the model generates a positive significant result for the parking variable (0.019; with s.e. 0.008). In our model, parking seems thus a measure for agglomerations and density (Chen et al., 2008).

Further research could shed more light on the different spatial patterns which are found at the origin and the destination side of the commuting trip. The different definitions employed in the two questionnaires may be one of the causes. The term carpooling covers a broad range of travel arrangements and a deeper insight can be obtained by analysing the differences across regions and activity sectors with regard to the different types of carpooling. Furthermore, the inclusion of small workplaces would increase the scope of the research. More advanced research designs could lead to a better understanding of the effectiveness of mobility management measures that promote carpooling. One could focus on the interdependencies between measures that promote different modes since competition between public transport and carpooling might occur. Finally, we did not investigate the time dimension in this paper. The dramatic decline in carpooling in the US received considerable attention (Ferguson, 1997a), but it is yet unclear what the effect would be of expected higher fuel prices (peak oil) (Gilbert and Perl, 2008; Wegener, 2011).

\section{Conclusion}

Both governments and employers promote carpooling as a commuting alternative in order to reduce the number of single occupant vehicle (SOV) users. This paper takes the workplace as prime research unit. The Belgian questionnaire home-to-work-travel (HTWT) proved to be a unique source of data generated at the worksite level. We controlled for three factors which could explain the differences in carpool shares at workplaces. A first relevant characteristic of a workplace is its location, which influences its accessibility. Second, organisational factors such as work schedules and the activity sector determine the attractiveness of carpooling. To account for the nesting of workplaces in activity sectors, we chose a two-level multilevel model which simultaneously modelled both the worksite and the economic sector levels. Third, employers promote carpooling by mobility management measures such as carpool databases, preferential parking and emergency ride home services. However, a model which checked for location, 
organisation and promotion, left the majority of the variance in carpooling unexplained. Despite the relative low explanatory power of the model, the analysis gives insight in the distribution of carpooling among workplaces in Belgium.

The most carpool-oriented sectors are construction and manufacturing and also in the wholesale and retail sectors carpool is popular. Carpooling is rather unpopular at universities, in the health sector and in public transport companies, and seems to be an alternative at locations where rail is no real alternative. Regular work schedules and a smaller number of employees at a site are positively correlated with a higher share of carpooling employees. For the effectiveness of carpool promoting measures no evidence could be found, except for the guaranteed ride home. Measures that discourage car use, like parking charges, seem to be more effective than soft carpool-promoting initiatives. Finally, we argue that the promotion of carpooling must not result in more car-oriented development and lower levels of cycling and using public transport .

\section{Acknowledgements}

This research is conducted within the ADICCT-project (Assessing and Developing Initiatives of Companies to control and reduce Commuter Traffic) which is financed by Belgian Science Policy in the Science for a Sustainable Development research programme. We are also grateful to Grégory Vandenbulcke (UCL) and the FPS Mobility and Transport for delivering data and information. The authors are grateful for advice from the anonymous referees.

\section{References}

Anselin, L., 1995. Local Indicators of Spatial Association-LISA. Geographical Analysis 27, 93-115.

Anselin, L., 2005. Exploring Spatial Data with GeoDa ${ }^{\mathrm{TM}}$ : A Workbook. Center for Spatially Integrated Social Science, Urbana.

Bonham, J. and Koth, B., 2010. Universities and the cycling culture. Transportation Research Part D 15, 94-102.

Boussauw, K. and Witlox, F., 2009. Introducing a commute-energy performance index for Flanders. Transportation Research Part A-Policy and Practice 43, 580-591.

Buehler, R., 2011. Determinants of transport mode choice: a comparison of Germany and the USA. Journal of Transport Geography 19, 644-657.

Buliung, R.N., Soltys, K., Bui, R., Habel, C., and Lanyon, R., 2010. Catching a ride on the information super-highway: toward an understanding of internet-based carpool formation and use. Transportation 37, 849-873.

Cairns, S., Sloman, L., Newson, C., Anable, J., Kirkbride, A., and Goodwin, P., 2008. Smarter choices: Assessing the potential to achieve traffic reduction using 'soft measures'. Transport Reviews 28, 593-618. 
Canning, P.E., Hughes, S.J., Hellawell, E.E., Gatersleben, B.C.M., and Fairhead, C.J., 2010. Reasons for participating in formal employer-led carpool schemes as perceived by their users. Transportation Planning and Technology 33, 733-745.

Chen, C., Gong, H., and Paaswell, R., 2008. Role of the built environment on mode choice decisions: additional evidence on the impact of density. Transportation 35, 285-299.

Comsis Corporation, 1993. A guidance manual for implementing effective employer-based travel demand management programs. The Institute of Transportation Engineers, Washington

Correia, G. and Viegas, J.M., 2011. Carpooling and carpool clubs: Clarifying concepts and assessing value enhancement possibilities through a Stated Preference web survey in Lisbon, Portugal. Transportation Research Part A 45, 81-90.

DeHart-Davis, L. and Guensler, R., 2005. Employers as Mediating Institutions for Public Policy: The Case of Commute Options Programs. Policy Studies Journal 33, 675-697.

Ferguson, E., 1997a. The rise and fall of the American carpool: 1970-1990. Transportation 24, 349-376.

Ferguson, E., 1997b. Privatization as choice probability, policy process and program outcome: The case of transportation management associations. Transportation Research Part A: Policy and Practice 31, 353364.

Ferguson, E., 2000. Travel Demand Management and Public Policy. Ashgate, Aldershot, UK.

Ferguson, E., 2007. Transportation Management Associations: A Reappraisal. Journal of Public Transportation 10, 1-26.

Frändberg, L. and Vilhelmson, B., 2010. Structuring Sustainable Mobility: A Critical Issue for Geography. Geography Compass 4, 106-117.

Gardner, B. and Abraham, C., 2007. What drives car use? A grounded theory analysis of commuters' reasons for driving. Transportation Research Part F 10, 187-200.

Getis, A., 2007. Reflections on spatial autocorrelation. Regional Science and Urban Economics 37, 491496.

Gilbert, R. and Perl, A., 2008. Transport Revolutions - Moving People and Freight without Oil. Earthscan, London, UK.

Giuliano, G., Hwang, K., and Wachs, M., 1993. Employee trip reduction in Southern California: First year results. Transportation Research Part A: Policy and Practice 27, 125-137.

Goldstein, H., 1995. Multilevel Statistical Models. Arnold, London

Habib, K.M.N., Tian, Y., and Zaman, H., 2011. Modelling commuting mode choice with explicit consideration of carpool in the choice set formation. Transportation 38, 587-604.

Heinen, E., Maat, K., and van Wee, B., 2011. The role of attitudes toward characteristics of bicycle commuting on the choice to cycle to work over various distances. Transportation Research Part D 16, 102-109.

Hox, J.J., 2002. Multilevel Analysis: Techniques and Applications. Erlbaum, Mahwah, NJ. 
Huang, H.-J., Yang, H., and Bell, M.G.H., 2000. The models and economics of carpools. Annals of Regional Science 34, 55-68.

Hwang, K. and Giuliano, G., 1990. The Determinants of Ridesharing: Literature Review. UCTC, Berkeley, California.

Kingham, S., Dickinson, J., and Copsey, S., 2001. Travelling to work: will people move out of their cars. Transport Policy 8, 151-160.

Legendre, P., 1993. Spatial Autocorrelation: Trouble or New Paradigm? Ecology 74, 1659-1673.

Luke, D.A., 2004. Multilevel Modeling. Sage, Thousand Oaks.

Luyten, S. and Van Hecke, E., 2007. De Belgische Stadsgewesten 2001. Statistics Belgium Working Paper, Brussels.

Lyons, G. and Urry, J., 2005. Travel time use in the information age. Transportation Research Part A 39, 257-276.

Maas, C.J.M. and Hox, J.J., 2004. Robustness issues in multilevel regression analysis. Statistica Neerlandica 58, 127-137.

McDonald, N.C., 2007. Travel and the social environment: Evidence from Alameda County, California. Transportation Research Part D 12, 53-63.

Meek, S., Ison, S., and Enoch, M., 2008. Role of Bus-Based Park and Ride in the UK: A Temporal and Evaluative Review. Transport Reviews 28, 781-803.

Meersman, H., Pauwels, T., and Van de Voorde, E., 1998. Bouwen aan een duurzame mobiliteit - Het woon-werkverkeer in de Belgische bouwsector: situering, analyse en strategische alternatieven. Tijdschrift Vervoerswetenschap 34, 361-377.

Menczer, W.B., 2007. Guaranteed Ride Home Programs: A Study of Program Characteristics, Utilization, and Cost. Journal of Public Transportation 10, 131-149.

Morency, C., 2007. The ambivalence of ridesharing. Transportation 34, 239-253.

O'Fallon, C., Sullivan, C., and Hensher, D.A., 2004. Constraints affecting mode choices by morning car commuters. Transport Policy 11, 17-29.

Parkhurst, G., 2000. Influence of bus-based park and ride facilities on users' car traffic. Transport Policy 7, 159-172.

Rasbash, J., Steele, F., Browne, W., and Prosser, B., 2005. A User's Guide to MLwiN Version 2.0. Centre for Multilevel Modelling University of Bristol, Bristol.

Rasbash, J., Steele, F., Browne, W.J., and Goldstein, H., 2009. A User's Guide to MLwiN - version 2.10. Centre for Multilevel Modelling, University of Bristol, Bristol.

Reniers, G., Dullaert, W., and Visser, L., 2010. Empirically based development of a framework for advancing and stimulating collaboration in the chemical industry (ASC): creating sustainable chemical industrial parks. Journal of Cleaner Production 18, 1587-1597. 
Rietveld, P., Zwart, B., van Wee, B., and van den Hoorn, T., 1999. On the relationship between travel time and travel distance of commuters - Reported versus network travel data in the Netherlands. Annals of Regional Science 33, 269-287.

Roby, H., 2010. Workplace travel plans: past, present and future. Journal of Transport Geography 18, 2330.

Rye, T., 1999a. Employer attitudes to employer transport plans: a comparison of UK and Dutch experience. Transport Policy 6, 183-196.

Rye, T., 1999b. Employer transport plans - a case for regulation? Transport Reviews 19, 13-31.

Rye, T., 2002. Travel plans: do they work? Transport Policy 9, 287-298.

Schwanen, T., Dieleman, F.M., and Dijst, M., 2004. The Impact of Metropolitan Structure on Commute Behavior in the Netherlands: A Multilevel Approach. Growth and Change 35, 304-333.

Shoup, D.C., 1997. Evaluating the effects of cashing out employer-paid parking: Eight case studies. Transport Policy 4, 201-216.

Teal, R.F., 1987. Carpooling - Who, How and Why. Transportation Research Part A 21, 203-214.

Tsao, H.-S. and Lin, D.-J., 1999. Spatial and Temporal Factors in Estimating the Potential of Ride-sharing for Demand Reduction. California PATH Research Report, UCB-ITS-PRR-99-2,

Van Acker, V., van Wee, B. and Witlox, F., 2010. When transport geography meets social psychology: toward a conceptual model of travel behaviour. Transport Reviews 30, 219-240.

Van Acker, V., Mokhtarian, P.L. and Witlox, F., 2011. Going soft: On how subjective variables explain modal choices for leisure travel. European Journal of Transport and Infrastructure Research 11, 115-146.

Vandenbulcke, G., Steenberghen, T., and Thomas, I., 2007. Accessibility indicators to places and transports: Final Report. Belgian Science Policy and FPS Mobility and Transports, Brussels.

Vandenbulcke, G., Steenberghen, T., and Thomas, I., 2009. Mapping accessibility in Belgium: a tool for land-use and transport planning? Journal of Transport Geography 17, 39-53.

Vanoutrive, T., Van Malderen, L., Jourquin, B., Thomas, I., Verhetsel, A., and Witlox, F., 2010. Mobility Management Measures by Employers: Overview and Exploratory Analysis for Belgium. European Journal of Transport and Infrastructure Research 10, 121-141.

Vanoutrive, T., Van Malderen, L., Jourquin, B., Thomas, I., Verhetsel, A., and Witlox, F., 2012. Rail Commuting to Workplaces in Belgium: A Multilevel Approach. International Journal of Sustainable Transportation 6, 67-87.

Verhetsel, A., Van Hecke, E., Thomas, I., Beelen, M., Halleux, J.-M., Lambotte, J.-M., Rixhon, G., and Mérenne-Schoumaker, B., 2009. Pendel in België. FOD Economie,K.M.O.,Middenstand en Energie, Brussels.

Wang, R., 2011. Shaping carpool policies under rapid motorization: the case of Chinese cities. Transport Policy 18, 631-635.

Wegener, M., 2011. From Macro to Micro - How Much Micro is too Much? Transport Reviews 31, 161177. 
Whitmeyer, J.M., 1994. Why Actor Models Are Integral to Structural Analysis. Sociological Theory 12, 153-165. 


\section{abstract}

Home to work travel remains the prime focus of mobility management policies, in which the promotion of carpooling is one of the main strategies. Besides governments, employers are key players in this strive for a more sustainable commute. However, commuting research tends to focus on individual commuters and their place of residence, rather than on workplaces and company-induced measures. Therefore, this paper takes the workplace as research unit to analyse the popularity of carpooling in Belgium. After an exploratory (spatial) data analysis, we incorporate three groups of factors in a multilevel regression model which predicts the share of carpooling at large workplaces: location (accessibility), organisation (activity sector), and promotion (carpool-oriented mobility management measures). Higher levels of carpooling are found at less accessible locations, and in the activity sectors construction, manufacturing and transport. This analysis gives insight in the determinants of carpooling, and may thus contribute to the development of sustainable transport policies.

Keywords: carpool; commuting; Belgium; mobility management; multilevel modelling

\section{Research Highlights}

-We model the share of carpooling in commuting at large workplaces in Belgium.

-Mobility management policies promote carpooling as sustainable commuting alternative.

-Carpooling is more popular at workplaces with limited accessibility by rail.

-There are more carpooling employees in construction, manufacturing and transport.

-The promotion of carpooling must not result in more car-oriented development and lower levels of cycling and using public transport. 
Thomas Vanoutrive

Department of Transport and Regional Economics, University of Antwerp and Department of Geography, Ghent University

thomas.vanoutrive@ua.ac.be

Corresponding author

Elien Van De Vijver

Department of Transport and Regional Economics, University of Antwerp and Department of Geography, Ghent University

elien.vandevijver@ugent.be

Laurent Van Malderen

Facultés Universitaires Catholiques de Mons (FUCaM) and Université catholique de Louvain, C.O.R.E. laurent.vanmalderen@fucam.ac.be

Bart Jourquin

Facultés Universitaires Catholiques de Mons (FUCaM)

bart.jourquin@fucam.ac.be

Isabelle Thomas

Université catholique de Louvain, C.O.R.E.

isabelle.thomas@uclouvain.be

Ann Verhetsel

Department of Transport and Regional Economics, University of Antwerp

ann.verhetsel@ua.ac.be

Frank Witlox

Department of Geography, Ghent University

frank.witlox@ugent.be 